they were in some sort original. You mention as a kind of palliative that, although my priority is not distinctly admitted, my name is mentioned in a prominent manner.

Personally I consider this a very small affair. Long experience of having my name mentioned in a similar manner, or mixed up with the names of others, or altogether omitted in connection with certain coal-dust matters in which I have undeniable priority, has hardened me; and I confess that this part of your letter gave me no concern. But although I could afford to pass it over in this way as far as I am myself concerned, I cannot adopt the same course when the interests of some of the members of the Royal Commission on Accidents in Mines are also at stake.

I must therefore ask you to give me a token of your good faith by restraining your friends from publishing anything further until the English Royal Commissioners shall have seen fit to make known the results obtained here. At the same time also I would suggest it as a simple matter of duty on your part to take immediate steps to let it be known to those before whom your friends' communications have appeared that the credit, if any, of the original investigations in this case rests with Sir Frederick Abel and Mr. W. Thomas Lewis quite as much as with me. Believe me yours very faithfully,

IV. Galloway

Herr Bergrath Kreischer, Professor der Bergbaukunde, Freiberg, Sachsen

\section{The Resting Position of Oysters}

IN books on Conchology, such as Woodward's "Manual of the Mollusca " and Jeffrey's "British Conchology," it is stated that the oyster rests in the natural state on its left valve, which is the larger and more convex. In this respect it is pointed out the oyster differs from the animals belonging to the genera Pecten and Anomia, which rest on the right valve, the Anomias being firmly attached by muscle with the flat right valve applied closely to the surface of attachment. In his lecture on oysters at the Royal Institution, which was published in Nos. I and of the English Illustrated Magazine, Prof. Huxley also states that oysters rest on the left or convex valve, the flat right valve acting as a kind of operculum. Examination of oysters from the Firth of Forth has convinced me that this statement is erroneous. I do not know on what evidence the current belief of conchologists is founded. The evidence which appears to me conclusive is that the right flat valve is always quite clean, while the convex valve is covered with worm tubes, Styela grossularia, and Hydroids. The latter are in this connection the most important ; it would be impossible for specimens of Sertularia and Thuiaria 4 or 5 inches long to grow, as I have found them on almost every oyster, in the central part of the left valve, if that valve were the lower in position. On examining Pectens I found that they resembled the oyster in the contrast between the surfaces of the two valves, the upper convex one being covered with Balanus and other fixed animals, the lower being almost clean. It is generally stated that the Pecten lies on its right valve; if this statement rests on the evidence afforded by the condition of the surface of the valves the same criterion applied to the oyster leads to the same conclusion, that the right valve is the lower. I have never seen a young oyster in the attached condition: Huxley states that it is the left valve which is fixed ; in papers on the embryology of the oyster I have not yet been able to find any definite information on the point. Whether it is the right or left valve that becomes attached when the larva assumes the sessile condition I cannot therefore say of my own knowledge, but with regard to the adult oyster it seems to me certain that the current belief is caused by the repetition of an error. My attention was first called to this point by my assistant, Mr. John Walker, who tells me that the opinion of the fishermen at Newhaven is divided on the point, some saying that the convex valve, others that the flat valve, is the lower.

Scottish Marine Station, Granton, October I4

$$
\text { J. T. Cunningham }
$$

\section{Two Generalisations}

Two generalisations seem to have been staring us in the face for some time, and yet I have seen no one give them a look of recognition; they may be phantasms, but they seem solid enough :-

(I) That the number of elements is infinite; the most readily- formed types of ethereal vortices being the commonest, but our knowledge of them being only limited by the scarceness of the more complex forms, and not by any limit to the infinite varieties of complexity that may exist. Theil relative commonness being analogous to the relative sizes of the bodies of the solar system; a few Iarge, and always recognisable, and a greater number of examples as we descend in size to mere meteors. We already see that there are far more rare elements known than common ones.

(2) That the reduction of an electric current to heat in an imperfect conductor is solely due to the independent heatmotions of the molecules, which check and divert more and more of the current as their motions are larger; if there were no pre-existing heat-motions there would be nothing to resist a complete transmission of the current motion, and hence there would be no limit to conduction at the zero of temperature except the cohesion of the material.

Bromley, Kent

W. M. Flinders Petrie

\section{Meteors}

ON the morning of October I3, at $2 \mathrm{~h} .26 \mathrm{~m}$., I saw a fine meteor giving a bright flash at the end point and leaving a streak for about I2 seconds. It shot from the Lynx towards the pointers in Ursa Major, and while carefully fixing its direction relatively to the stars near, another conspicuous meteor, about as bright as Jupiter, crossed the lingering streak in a path but slightly inclined to it and of nearly similar length. I have never before observed two large meteors almost simultaneous and with paths so nearly identical.

I subjoin the observed paths of these meteors, also of five other bolides recently noted here during the progress of my habitual watches for shooting stars :-

\begin{tabular}{|c|c|c|c|c|c|c|}
\hline 1885 & G.M.T. & Mag. & From & To & Length & Radiant \\
\hline ept. 9 & I5 48 & 4 & I $49+82$ & $\stackrel{\circ}{152}+6^{\circ}$ & 18 & $335+7 \mathrm{I}$ \\
\hline$\times 5$ & I5 II & 4 & $37+6 \frac{1}{2}$ & $26 \frac{1}{2}+7$ & $10 \frac{1}{2}$ & $70+4$ \\
\hline Oct. & $105 \mathrm{I}$ & $2 !$ & $51 \frac{1}{2}+22$ & $7 \mathrm{I}_{\frac{1}{2}}+24$ & 18 & $3 x+18$ \\
\hline & I5 9 & 4 & $155+53$ & $162 \frac{1}{2}+46 \frac{1}{2}$ & 8 & $42+55$ \\
\hline , 12 & 1426 & 우 & $119+51$ & $I_{5} \mathrm{I}+60 \frac{1}{2}$ & 20 & $88+18$ \\
\hline , 12 & 1426 & 4 & $119 \frac{1}{2}+50$ & $143+60 \frac{1}{2}$ & $16 \frac{1}{2}$ & $103+33$ \\
\hline I6 & I6 35 & 24 & $2 \times 3+47 \frac{1}{2}$ & $226+4 I$ & II & $143+49$ \\
\hline
\end{tabular}

The radiant points are derived in each case by combination with many other meteors registered on about the same nights. I have seen 357 meteors since early in September, and those selected in the above table comprise all the brighter specimens estimated to equal Jupiter.

Bristol, October I 7

W. F. DENNING

\section{Statigrams}

THE increasing use of graphic representations of statistics by means of lines, areas, \&c., seems to render it convenient to have some word which would specially designate diagrams exhibiting the progress and tendencies of the numerous tables of figures which do not pretend to strict scientific accuracy. The word diagram is used in most elastic senses and by all sorts and conditions of men.

May I suggest the word statigraph as a definite and convenient one for adoption? This might be sometimes shortened to graph; whereas statigram, if preferred, would not admit of this abbreviation. Most, if not all, graphic results of statists, economists, anthropologists, \&c., might thus be termed graphs, whilst mathematicians and the experimental men of science would be left with the use of their own words, such as curves, indicator diagrams, \&c. Each class would possess its own degree and limits of accuracy: mathematical precision and the doctrine of energy would apply to the latter, but graphs would be understood to involve human elements with intricate factors whose recognition or relationships the statistics are intended to elucidate and compare rather than to define and measure.

I2, Merton St., Oxford

J. F. Heyes

\section{THE GEOLOGICAL SURVEY OF BELGIUM}

PROBABLY no country of Europe has had its geology more attentively studied and mapped than Belgium. From the early labours of the veteran and pioneer 